\title{
Discrimination of Rapid and Gradual Deterioration for an Enhanced Gas Turbine Life-Cycle Monitoring and Diagnostics
}

\author{
Amare Fentaye $^{1}$, Valentina Zaccaria $^{2}$, and Konstantinos Kyprianidis ${ }^{3}$ \\ ${ }^{1,2,3}$ School of Business, Society and Engineering, Mälardalen University, 72123 Västerås, Sweden \\ Amare.desalegn.fentaye@mdh.se \\ valentina.zaccaria@mdh.se \\ konstantinos.kyprianidis@mdh.se
}

\begin{abstract}
Advanced engine health monitoring and diagnostic systems greatly benefit users helping them avoid potentially expensive and time-consuming repairs by proactively identifying shifts in engine performance trends and proposing optimal maintenance decisions. Engine health deterioration can manifest itself in terms of rapid and gradual performance deviations. The former is due to a fault event that results in a short-term performance shift and is usually concentrated in a single component. Whereas the latter implies a gradual performance loss that develops slowly and simultaneously in all engine components over their lifetime due to wear and tear. An effective engine lifecycle monitoring and diagnostic system is therefore required to be capable of discriminating these two deterioration mechanisms followed by isolating and identifying the rapid fault accurately. In the proposed solution, this diagnostic problem is addressed through a combination of adaptive gas path analysis and artificial neural networks. The gas path analysis is applied to predict performance trends in the form of isentropic efficiency and flow capacity residuals that provide preliminary information about the deterioration type. Sets of neural network modules are trained to filter out noise in the measurements, discriminate rapid and gradual faults, and identify the nature of the root cause, in an integrated manner with the gas path analysis. The performance of the proposed integrated method has been demonstrated and validated based on performance data obtained from a three-shaft turbofan engine. The improvement achieved by the combined approach over the gas path analysis technique alone would strengthen the relevance and long-term impact of our proposed method in the gas turbine industry.
\end{abstract}

\footnotetext{
Amare Fentaye et al. This is an open-access article distributed under the terms of the Creative Commons Attribution 3.0 United States License, which permits unrestricted use, distribution, and reproduction in any medium, provided the original author and source are credited.

https://doi.org/10.36001/IJPHM.2021.v12i3.2962
}

\section{INTRODUCTION}

In the competitive aviation industry, improving the gas turbine maintenance strategy plays a major role in the business. This may demand a more advanced decisionmaking process through the support of an effective engine health management (EHM) technology. An effective engine life-cycle monitoring and diagnostics system development requires a comprehensive knowledge on engine deterioration mechanisms. Engine performance deteriorates through time due to different internal and external conditions and can be recoverable or non-recoverable in its nature. Recoverable deterioration mainly refers to shortterm performance losses caused by single fault events that can be restored during operation or engine overhauls. Nonrecoverable deterioration refers to long-term or gradual performance losses that develop slowly and simultaneously in all engine components over their lifetime due to wear and tear (Jiang \& Foster, 2013). Repairing or replacing the irreversible defective part of the engine is the solution to restore the lost performance due to permanent deterioration/ structural changes (Boyce \& Gonzalez, 2005). The aim of a fault diagnostics process is, therefore, to assess performance losses due to engine degradation and suggest a proactive solution at the earliest possible. Apparently, this will help the operators to act so that the engine can be restored to its best possible performance.

For a typical gas turbine engine in service, gas path measurement trend shifts occur with time due to gradual deterioration. Performance losses caused by this fault can be predicted based on a time series analysis. When a rapid or an abrupt fault occurs on the engine gas path, a sudden trend shift will be observed in one or more of the measurements. An abrupt fault is a fault event that appears instantaneously and remains fixed in magnitude with time, while a rapid fault refers to a fault event that initiates and grows in magnitude with time (Simon, 2010b). All these three fault mechanisms have, therefore, distinguishable measurement signatures. A rapid or an abrupt fault is detectable if and 
only if the associated trend shifts exceed the effect of measurement noise. Once a sudden and persistent measurement shift has been detected in the time series, identifying the nature of the fault is the next step.

Discriminating between rapid and gradual deterioration is one of the most important steps in the EHM process. Since these two deterioration mechanisms can simultaneously exist, ignoring any one of them will result in a poor maintenance decision. However, due to the challenges of solving them using a single technique, most of the past studies addressed them separately applying two complementary methods (Marinai, Singh, Curnock, \& Probert, 2003). The available methods can be categorized as analytical, empirical, and hybrid (Amare Desalegn Fentaye, Baheta, Gilani, \& Kyprianidis, 2019; Tahan, Tsoutsanis, Muhammad, \& Karim, 2017; Zhao, Wen, \& Li, 2016). Hybrid methods aim at incorporating advantages of the analytical and empirical methods along with overcoming their shortcomings. Some of the most popular methods are Gas path analysis (GPA) (Aretakis, Mathioudakis, \& Stamatis, 2003; Li, 2010; Mathioudakis \& Kamboukos, 2004; Zaccaria, Stenfelt, Aslanidou, \& Kyprianidis, 2018), Kalman filter (KF) (Dewallef, Romessis, Léonard, \& Mathioudakis, 2004; Lu, Gao, Huang, \& Qiu, 2019; Pourbabaee, Meskin, \& Khorasani, 2015), Artificial neural network (ANN) (Loboda \& Olivares Robles, 2015; Xuyun, Hui, Zhong, \& Lin, 2019), Fuzzy logic (FL) (Fentaye, Baheta Aklilu, \& Gilani Syed Ihtsham, 2018; R. Ganguli, 2003; Mohammadi \& Montazeri-Gh, 2015), Bayesian network (BN) (Lee, Mavris, Volovoi, Yuan, \& Fisher, 2010; Mathioudakis \& Romessis, 2016), and Support vector machine (SVM) (Fentaye, Syed, Baheta, \& Li, 2018; Zhou, Zhang, \& Weng, 2015).

The common GPA procedure required to separate rapid and gradual deterioration was described by Volponi (2014). It is a component level performance analysis scheme based on thermodynamic relationships. This approach has been implemented in the real EHM process almost from the inception of a gas turbine. A data-driven anomaly detection algorithm was devised through the fusion of gas turbine principles and nonlinear autoregressive with exogenous inputs network. Data patterns extracted from a brand new engine operated for a short period of time were used to train and validate this algorithm (Bai, Liu, Chai, Zhao, \& Yu, 2020). Tang, Tang, and Chen (2019) implemented a transfer-learning with multiple ANN models to overcome trend shift problems due to engine overhauls. Their proposed diagnostic method can automatically update its training data, after every maintenance event, and maintain a consistent diagnostic accuracy throughout the engine life. Losi, Venturini, Manservigi, Ceschini, and Bechini (2019) assessed the capability of Bayesian hierarchical models (BHM) detecting sensor faults in gas turbine time series based on field data.
To overcome the available inconsistency in the literature in defining and representing EHM problems, the NASA Glenn Research Center set a benchmark problem for aircraft engine gas path diagnostics. According to this benchmark problem, gradual deterioration is not considered as a fault. Practical diagnostic tools should, therefore, be able to detect and isolate rapid/abrupt faults in a deteriorated engine (Simon, 2010a). They addressed the problem through a combination of trend monitoring and anomaly detection and diagnostic logic. As a case study, the capability of Weighted least squares (WLS), Probabilistic neural network (PNN), Extended Kalman filter (EKF) combined with Regularized least squares, and Generalized observer based diagnostic techniques was evaluated by the research center (Simon, Borguet, Léonard, \& Zhang, 2014). Based on their assessment findings, it was recommended to combine classification methods with the best accuracy as a future research direction. Jaw and Lee (2014) evaluated the effectiveness of five different machine learning classifiers for a two-shaft aero-engine single fault classification. However, a fleet of engines that experience only abrupt and rapid faults were considered here.

Overall, research on rapid and gradual degradation discrimination is limited. Recently, Hanachi, Liu, Banerjee, and Chen (2015) developed a model based short-term and long-term performance monitoring and diagnostic approach for single-shaft industrial gas turbine engines. They used two performance parameters (power loss index and heat loss index) to represent deterioration. The performance of six different diagnostic methods to deal with compressor, sensor, and actuator faults in a fleet of deteriorated twoshaft turbofan engines was evaluated by Koskoletos, Aretakis, Alexiou, Romesis, and Mathioudakis (2018). Loboda, Pérez-Ruiz, and Yepifanov (2018) also compared three popular data-driven techniques, namely multilayer perceptron (MLP), PNN, and SVM for fleet monitoring.

Our proposed diagnostic framework constitutes an adaptive gas path analysis (AGPA) and three ANN models. The AGPA based trend monitoring approach is applied to capture gradual performance changes in terms of isentropic efficiency and flow capacity residuals. Sudden trend shifts of the two health parameter residuals are also used as preliminary information about the occurrence of faults prior to implementing the ANN models. Particularly, two auto associative neural network (AANN) models are trained to remove noise from data, separate rapid and gradual deteriorations, and identify rapid faults based on the AGPA outputs. Blead valve leakages (BVL) are quantified separately using a multilayer perceptron (MLP). Data samples drawn from different component and leakage fault scenarios are used to demonstrate and validate the performance of the proposed method in a three-spool highby-pass turbofan engine. Intermediate-pressure compressor (IPC), high-pressure compressor (HPC), high-pressure turbine (HPT), intermediate-pressure turbine (IPT), and 
low-pressure turbine (LPT) are the gas path components considered in the analysis. The effectiveness of the AGPA scheme with and without the denoising process has also been compared in the end. The contribution of this paper can be summarized as follows:

- In EHM, separating rapid and gradual deterioration is necessary. There are limited studies conducted to address this problem. The available methods applied a trend monitoring logic or a time series analysis on measurement residuals to distinct between slow and rapid changes, followed by root cause identification based on measurement deltadelta. In the current work, health parameter residuals (isentropic efficiency and flow capacity deltas) are used instead. Hence, the proposed method can be an alternative approach in this field.

- AGPA and ANN are integrated in a novel way to separate rapid/abrupt and gradual deterioration trends occurring simultaneously, isolate the fault type and quantify its magnitude.

- AGPA based diagnostic models are advantageous to update the baseline performance when required upon a considerable performance shift after engine overhauls or maintenance events. The updating process requires less data than data-driven techniques (Tang et al., 2019).

- Using AANNs for rapid fault classification based on isentropic efficiency and flow capacity residuals is a new concept. Besides, since the accuracy of a diagnostic method is impacted by a measurement noise, using the AANN for denoising is beneficial.

- The leakage fault quantification procedure is also the other advantage of the proposed method, as there are limited studies conducted in this regard.

\section{ENGINE DIAGNOSTIC PROBLEM}

In an engine service history, simultaneous existence of rapid and gradual deterioration is likely. Diagnostic algorithms developed for rapid deterioration estimation will result in untrustworthy results for gradual deterioration and vice versa. Separating the two degradation mechanisms is, therefore, crucial in an engine life-cycle monitoring (Volponi, 2014). It is important to define the failure mode and select the appropriate forecasting algorithm in the stage of prognostics (Marinai et al., 2003). The engine gas path components performance parameters and measurements are the variables to be investigated. For each fault scenario, the performance parameter deltas or health indices $(\mathrm{Li}, 2010)$ are estimated by subtracting the values at the current state of the engine from the baseline performance. The current state of the engine can be determined through an adaptive model from the measured data. Besides, as engine measurements are subject to changes due to ambient condition variations and noise, data processing is necessary prior to the diagnostic task for a robust solution.

The diagnostic problem was defined based on the following key definitions and assumptions:

- Short term degradation: sudden performance changes due to abrupt or rapid faults.

- Long term degradation: slow/gradual performance changes of all the engine components simultaneously due to permanent structural damages caused by fouling, erosion, and corrosion based mechanical wear and tear.

- The magnitude of rapid faults is assumed to increase linearly with each flight, from the flight of fault initiation up until the flight where the maximum severity is reached.

- As stated in the introduction, abrupt faults do not progress in magnitude once they appear.

- Gradual degradation is not considered a fault.

- Short-term faults shall not exist simultaneously.

\section{Methodology}

In the proposed diagnostic framework, as shown in Figure 1 , a combination of AGPA, AANN and MLP is implemented. The complete process involves three major activities: measurement correction, noise reduction, and fault diagnostics. The measurement correction task aims to filter out the effect of ambient condition variation, while the next step is dedicated to minimizing measurement noise. The final activity refers to fault diagnostics (i.e., discriminating between short-term and long-term degradation problems and isolating short-term faults together with quantifying their magnitude). Flow chart of the diagnostic steps is presented in Figure 2.

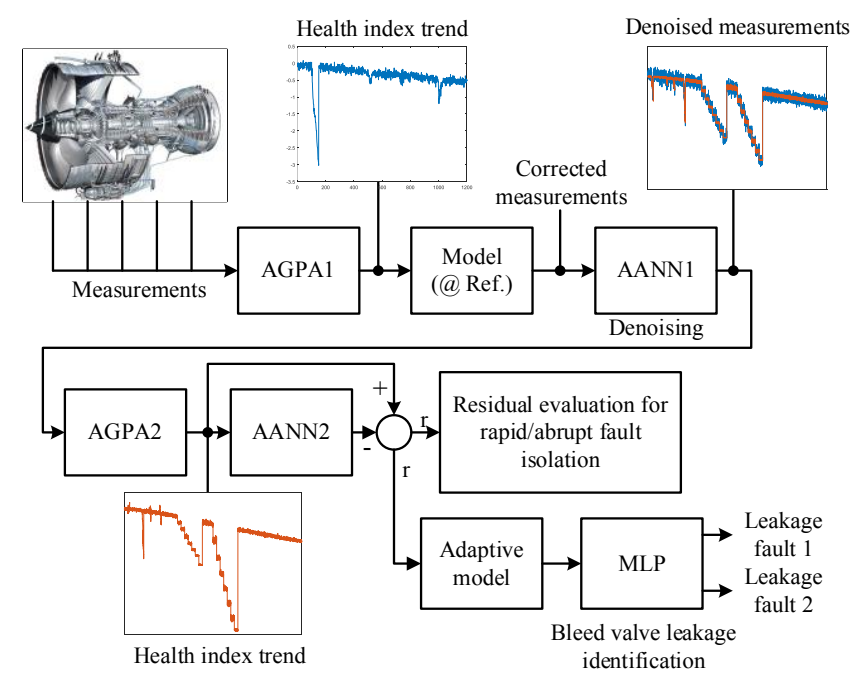

Figure 1. Schematic diagram of the proposed diagnostic framework. $r$ refers to health parameter residuals 


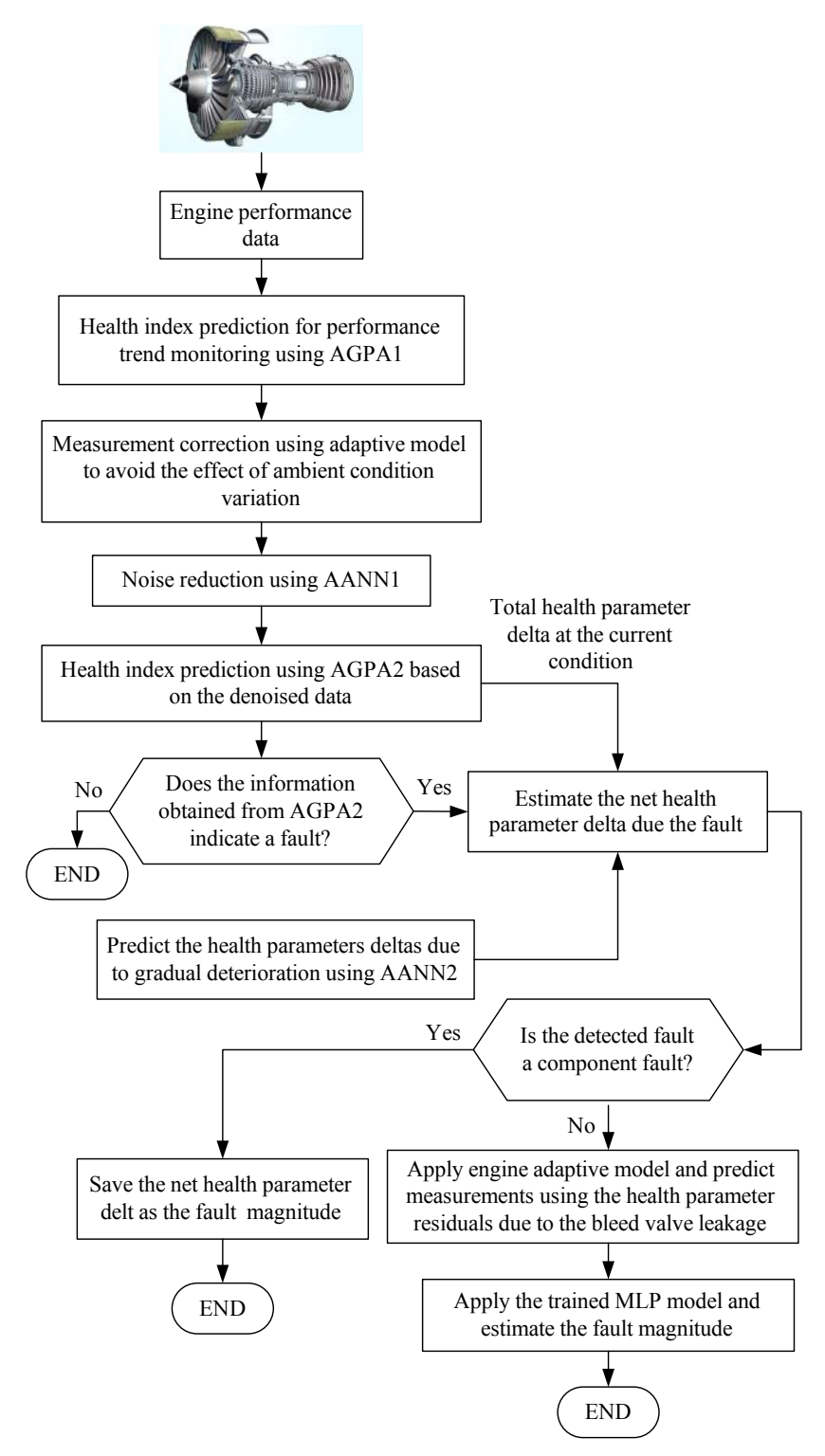

Figure 2. Process flow of the proposed method

\subsection{Adaptive Gas Path Analysis}

In performance-based diagnostics, the deviation of gas path parameters, such as temperatures and pressures, from the expected values is used to detect anomalies and identify the underlying cause. GPA based on a linear model of the gas turbine was first introduced by Urban in 1967 (Urban, 1969), and in the following decades, the method has evolved to include non-linear models, genetic algorithm optimization, artificial neural networks, and others $(\mathrm{Li}$, 2017; Marinai, Probert, \& Singh, 2004; Roumeliotis, Aretakis, Mathioudakis, \& Yfantis, 2012).

The principle of GPA is that by knowing the influence that expected anomalous conditions have on measured outputs, the latter can be directly linked to the cause and severity of the anomaly, as illustrated in Figure 3.

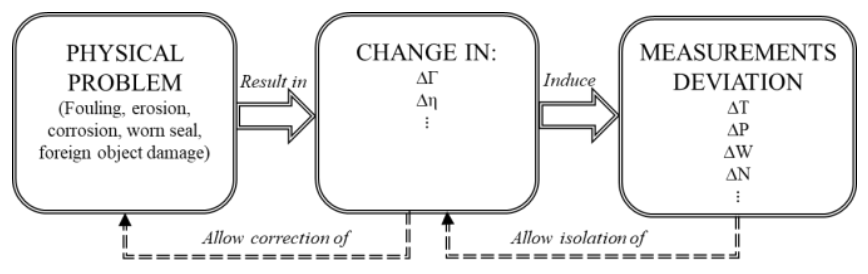

Figure 3. Gas path analysis schematics

Like the conventional GPA, AGPA assess the current health status of the engine based on gas path measurements, but an adaptive mode is used instead. Gas turbine adaptative modeling allows the performance simulation with the possibility of adapting to engine particularities. These particularities may include ambient condition, operating condition, and engine health (Visser, Kogenhop, \& Oostveen, 2004). In the current work, the three-spool, highbypass turbofan engine was modelled by means of the inhouse software EVA (Kyprianidis, 2017, 2019). In EVA, the various components, e.g. rotating components, combustor, diffusers, nozzle, and shafts are modelled as individual modules and are connected mechanically and thermodynamically as they would be in a real engine. A compressor and turbine performance is estimated based on characteristics maps. Gibbs free energy minimization under the assumption of ideal gases is used to model the combustion. Mass and energy balances are used to guarantee continuity among the components. The model is run either to a controlled fuel flow rate or to an exhaust gas temperature (EGT). The HPT Thermal Barrier Coating (TBC) average external surface blade metal temperature and corresponding cooling flows have been modelled using the simplified approach presented in (Van der Auweraer, Anthonis, De Bruyne, \& Leuridan, 2013).

For the purpose of diagnostics, deviation factors in isentropic efficiency and flow capacity of the main rotating components are introduced. The factors $\Delta \eta$ and $\Delta \Gamma$ are used to shift the characteristics map and simulate the effect of component degradation or faults. In the AGPA, the model varies the deviation factors until the outputs match a set of the target values, representing the measured data from the engine. The basic thermodynamic expressions for this analysis can be found in the literature (Lambiris, Mathioudakis, Stamatis, \& Papailiou, 1994; Fentaye, Baheta, Syed, \& Kyprianidis, 2019), however, a description of the main steps is given below:

For a given $\mathrm{N}$ number of health parameters required to be adapted and $\mathrm{M}$ number of target measurement parameters, the thermodynamic relationship can be expressed as

$$
\boldsymbol{\Delta} \boldsymbol{X}=\boldsymbol{J} \cdot(\boldsymbol{\Delta} \boldsymbol{Z})
$$

where $\Delta \mathbf{X}$ refers to the vector of measurement parameter deltas $\left(\Delta \mathrm{X}_{1}, \Delta \mathrm{X}_{2}, \ldots, \Delta \mathrm{X}_{\mathrm{M}}\right), \Delta \mathbf{Z}$ is the vector of health parameter deltas $\left(\Delta \mathrm{Zz}_{1}, \Delta \mathrm{Z}_{2}, \ldots, \Delta \mathrm{Z}_{\mathrm{N}}\right)$, and $\boldsymbol{J}$ is the Jacobian matrix also cold influence coefficient matrix 
(IFM), which defines the relationship between the measurement and health parameters vectors. Mathematically

$$
\boldsymbol{J}=\left[\begin{array}{cccccc}
\frac{\partial X_{1}}{\partial Z_{1}} & \frac{\partial X_{1}}{\partial Z_{2}} & \cdots & \frac{\partial X_{1}}{\partial Z_{k}} & \cdots & \frac{\partial X_{1}}{\partial Z_{N}} \\
\frac{\partial X_{2}}{\partial Z_{1}} & \frac{\partial X_{2}}{\partial Z_{2}} & \cdots & \frac{\partial X_{2}}{\partial Z_{k}} & \cdots & \frac{\partial X_{2}}{\partial Z_{N}} \\
\vdots & \vdots & \ddots & \vdots & \cdots & \vdots \\
\frac{\partial X_{i}}{\partial Z_{1}} & \frac{\partial X_{i}}{\partial Z_{2}} & \cdots & \frac{\partial X_{i}}{\partial Z_{k}} & \cdots & \frac{\partial X_{i}}{\partial Z_{N}} \\
\vdots & \vdots & \cdots & \vdots & \cdots & \vdots \\
\frac{\partial X_{M}}{\partial Z_{1}} & \frac{\partial X_{M}}{\partial Z_{2}} & \cdots & \frac{\partial X_{M}}{\partial Z_{k}} & \cdots & \frac{\partial X_{M}}{\partial Z_{N}}
\end{array}\right]
$$

Each matrix column represents the effect of a performance deviation factor on the measurement residuals. Starting from a guess value, the deviation factors are varied through an iterative procedure until the residuals are below a predefined threshold. Inverse of $\boldsymbol{J}$ (called the fault coefficient matrix $(\mathrm{FCM}))$ is used to compute the health parameter deltas.

It is important to note that the Jacobian matrix is square, hence the same number of target measurement variables and deviation factors is necessary. An observable influence of each deviation factor on at least a measured variable is also a necessary condition as explained in (Stenfelt, Zaccaria, \& Kyprianidis, 2019).

When the model run in performance simulation mode, rather than in diagnostic mode, the measurement deviation factors can be fixed and the resulting outputs are calculated. In this work, AGPA was run at an actual flight condition (i.e., at measured altitude, ambient temperature, Mach number, and fuel flow rate). During component fault estimation based on noisy data, the gas path analysis may overestimate some deviation factors and underestimate others (smearing effect) (Ying, Cao, Li, Li, \& Guo, 2016; Zedda \& Singh, 2002). Hence, once the deviation factors are estimated by the AGPA, these are fixed and the model is subsequently run with the adapted characteristics maps back to ISA reference conditions (Sea-level-static ISA conditions, max take-off power). The obtained outputs are, therefore, corrected with respect to ambient and power conditions, and their residuals are free from the deviations caused by these factors.

\subsection{Noise Reduction using Auto-associative Neural Network (AANN1)}

There are different denoising techniques available in the literature. Although linear filters such as the moving average have been widely used in the gas turbine industry, they have also known drawbacks. They tend to smooth out or distort the sharp trend shift edges which is critical in detecting abrupt faults and they are not good enough at removing measurement outliers (Uday \& Ganguli, 2010). Conversely, the nonlinear filters including AANNs are significantly more effective in removing noise and outliers while preserving sharp trend shifts in measurements due to faults (Sadough Vanini, Meskin, \& Khorasani, 2014; Verma \&
Ganguli, 2005). They are also capable of capturing the linear changes in measurements that can come from gradual degradation (Ranjan Ganguli, 2002). A denoising AANN, also known as a denoising autoencoder (DAE), applies the concept of nonlinear principal component analysis (NLPCA) to compress a high dimensional data into a low dimensional feature. Accordingly, AANN1 (Figure 4) is trained to minimize measurement noise in the turbofan engine. It allows to handover the nonlinearity of the engine data without affecting sharp trend shifts, unlike linear filters. In the training, noise-corrupted data was used as input and noise-free data as output. The network was then tested to reduce the noise and provide an output, which is as close as the desired noise-free output. The hyperparameters for the selected network architecture were determined through training (Kramer, 1991).

For noisy input vector $\mathbf{X}$, the denoising process in a AANN involves two sub-tasks, compression and decompression, which can be described as translations $\boldsymbol{\Omega}$ and $\boldsymbol{\Theta}$ :

$$
\begin{gathered}
\boldsymbol{\Omega}: \boldsymbol{X} \rightarrow \mathrm{H} \\
\boldsymbol{\Theta}: \mathrm{H} \rightarrow \boldsymbol{X}^{\prime} \\
\boldsymbol{\Omega}, \boldsymbol{\Theta}=\underbrace{\arg \min }_{\boldsymbol{\Omega}, \boldsymbol{\Theta}}\|\boldsymbol{X}-(\boldsymbol{\Theta} \cdot \boldsymbol{\Omega}) \boldsymbol{X}\|^{2}
\end{gathered}
$$

The compression section takes the input data $\boldsymbol{X}$ and maps it to a feature vector $\boldsymbol{H}$ by using the bottleneck layer. For a given subset of input data $\boldsymbol{x}$, the corresponding feature output $\boldsymbol{h}$ can be described as

$$
\boldsymbol{h}=f_{b l}\left(\boldsymbol{b}_{2}+\mathrm{W}_{2} \cdot f_{m l}\left(\boldsymbol{b}_{1}+\mathrm{W}_{1} \boldsymbol{x}\right)\right)
$$

where $f_{\mathrm{ml}}$ and $f_{\mathrm{bl}}$ represent the mapping layer $(\mathrm{ml})$ and bottleneck layer (bl) activation functions, respectively, and $\mathbf{b}_{1}, \mathbf{b}_{2}, W_{1}$, and $W_{2}$ refer to weight and bias vectors of the $\mathrm{ml}$ and $b l$, respectively.

Similarly, the output for the decompression process can be expressed as

$$
\boldsymbol{x}^{\prime}=f_{o l}\left(\boldsymbol{b}_{4}+\mathrm{W}_{4} \cdot f_{d m l}\left(\boldsymbol{b}_{3}+\mathrm{W}_{3} \boldsymbol{h}\right)\right)
$$

where $\boldsymbol{x}^{\prime}$ is the output of the network for a given input subset $\boldsymbol{x}, f_{\mathrm{dml}}$ and $f_{\mathrm{ol}}$ denote the demapping layer $(\mathrm{dml})$ and output layer (ol) activation functions, respectively, $\mathbf{b}_{3}, \mathbf{b}_{4}, W_{3}$, and $\mathrm{W}_{4}$ refer to weight and bias vectors of the $\mathrm{dml}$ and ol, respectively. For all layers, tan-sigmoidal activation function was used.

Usually, the mean square error (MSE), as shown in Eq. (6), is employed as the reconstruction loss to be minimized based on the backpropagation algorithm. Taking into consideration the overfitting problem, the process is repeated several times until the required output is achieved.

$$
M S E=\frac{1}{n} \sum_{i=1}^{n}\left(x_{i}-x_{i}^{\prime}\right)^{2}
$$

where $x_{i}$ is the target output value for input case $i, x_{i}^{\prime}$ is the reconstructed value, and $\mathrm{n}$ is the number of samples used. 


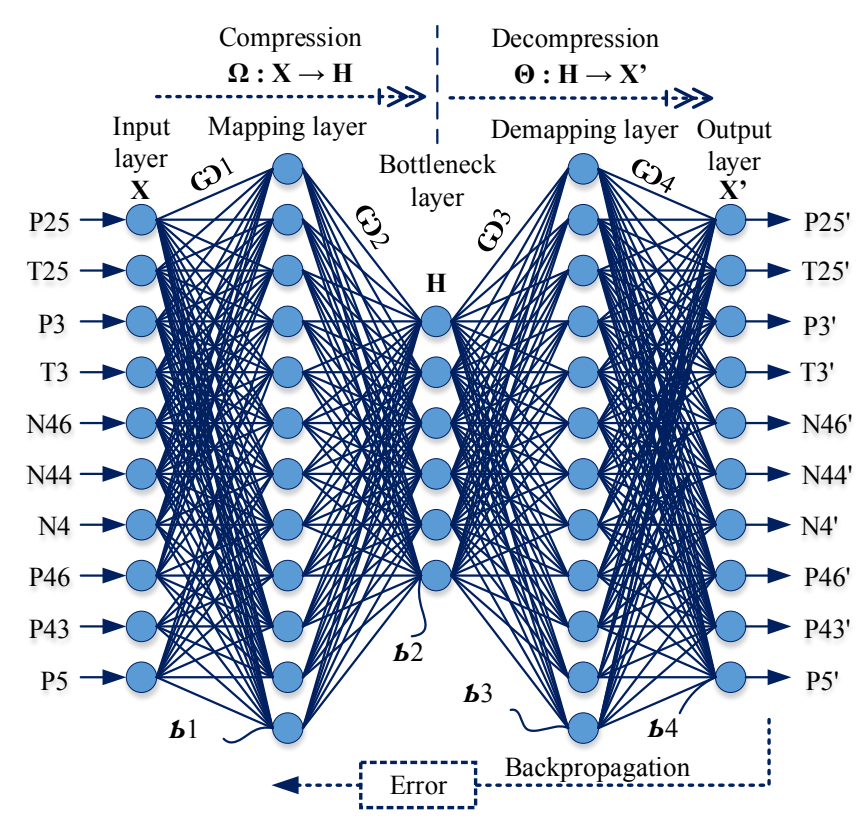

Figure 4. AANN1 structure used to remove noise from measurements. All measurements are used after the correction process is performed in the AGPA.

\subsection{Short-Term Fault Diagnostics Using AANN}

One of the possible ways to separate sudden performance shifts caused by short-term faults from gradual performance deviations is using a degraded engine model as a reference. There are different modeling approaches available for this (Wei, Zhang, Jafari, \& Nikolaidis, 2020). Exponential trajectory propagation is one among them. According to this approach, flow capacity and isentropic efficiency degradation profiles are modeled with time for each gas path component (Hanachi, Liu, Kim, \& Mechefske, 2019; Saxena, Goebel, Simon, \& Eklund, 2008). As reported by Litt, Parker, and Chatterjee (2003), the degradation trajectories tend to become more linear as the engine ages. Loboda et al., (2018) employed polynomial functions to plot measurement deviation trends for fleet engines. Differently, we applied an AANN to predict gradual deterioration in terms of isentropic efficiency and flow capacity indices. Outputs of the AGPA2 $\left(\Delta \eta_{\text {Comp_1 }}, \Delta \Gamma_{\text {Comp_1 }}, \Delta \eta_{\text {Comp }} 2\right.$, $\Delta \Gamma_{\text {Comp_2 }}, \ldots, \Delta \eta_{\text {Comp_k }}, \Delta \Gamma_{\text {Comp_k }}, \ldots, \Delta \eta_{\text {Comp_N }}$ and $\left.\Delta \Gamma_{\text {Comp_N }}\right)$ associated with the gradual deterioration were used as input/output of the network. Faults were then diagnosed based on the health parameter residuals estimated by subtracting AANN2 outputs from AGPA2 outputs. If no abrupt/rapid fault exists, all residuals will be close to zero or fall within some defined threshold due to the measurement noise effects. For example, if $F 1$ exists, only $\Delta \eta_{\text {IPC }}$ and $\Delta \Gamma_{\text {IPC }}$ residuals will exceed from the expected no-fault region. If a fault is isolated, the health parameter residuals will indicate to the magnitude of that fault.
Figure 5 illustrates schematically how the health parameter deltas were computed for rapid faults. It represents engine operation under three different health conditions. Section A, the region from flight $a$ to flight $b$, refers to engine operation under gradual degradation only. For this region, the health parameter deltas are estimated with reference to a clean engine performance. Section $\mathrm{B}$, the period from flight $\mathrm{b}$ to $\mathrm{c}$, delegates to engine operation with the simultaneous occurrence of both rapid and gradual degradation. It is assumed that the fault initiates at flight $b$ and grows rapidly at every flight until it reaches to its maximum severity at flight $\mathrm{c}$. In the last region, section $\mathrm{C}$, the rapid fault remains fixed at its maximum severity while the gradual degradation increases slowly with the engine flight cycle. Flights a, b, and $\mathrm{c}$ do not refer consecutive flight numbers.

Assume that $\Delta Z$ represents the health parameter deltas $(\Delta \Gamma$, $\Delta \eta)$. The health parameter delta at the $\mathrm{j}^{\text {th }}$ flight due to the rapid fault, $\Delta Z_{R}^{j}$, is the difference between the total delta due to the simultaneous deterioration, $\Delta Z_{T}^{j}$, and the delta due to the gradual deterioration at this flight, $\Delta Z_{G}^{j} . \Delta Z_{T}^{j}$ and $\Delta Z_{G}^{j}$ are estimated by the AGPA2 the AANN2, respectively, at the flight number $\mathrm{j}$. Mathematically, it can be formulated as

$$
\Delta Z_{R}^{j}=\Delta Z_{T}^{j}-\Delta Z_{G}^{j}
$$

For $\mathrm{N}$ number of gas path components with two health parameters each, the residual matrix can be expressed as

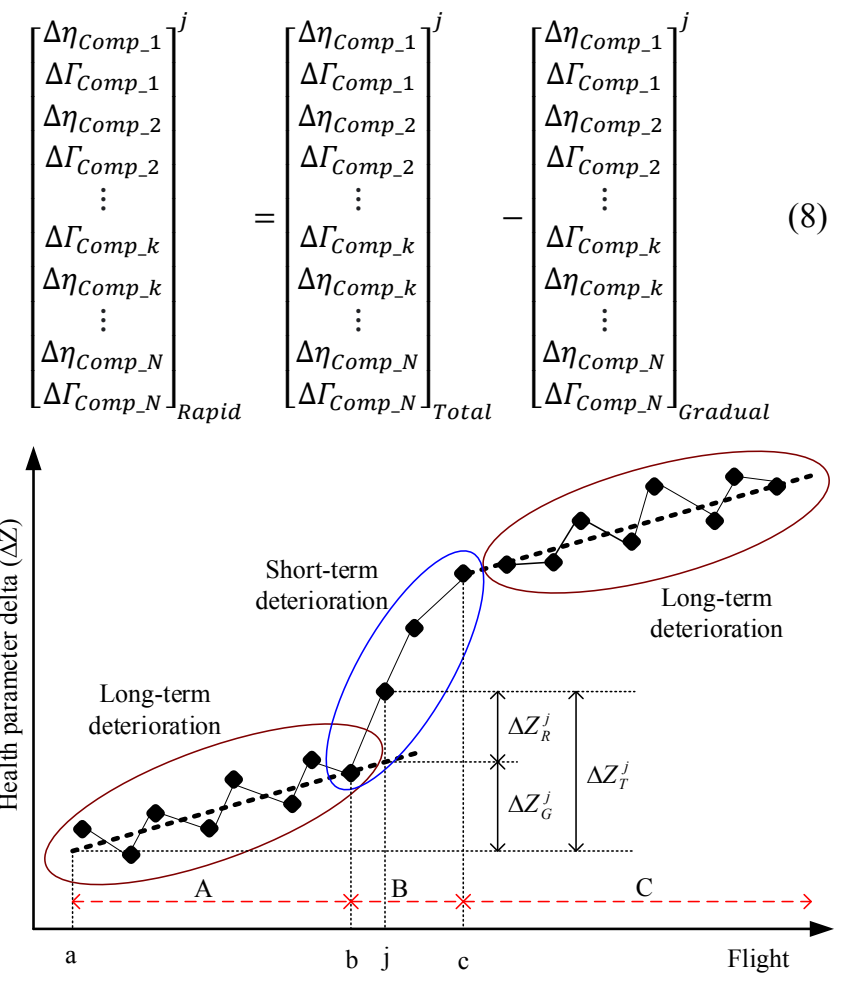

Figure 5. Health parameter delta estimation schematics for engine gradual degradation with a rapid fault occurrence. 
For abrupt faults, at a given fault magnitude, the health parameter deltas remain constant from the flight of fault initiation to the termination point upon a maintenance action. A schematic illustration is given in Figure 6. In this case, there are only two regions, A and B. After the abrupt fault occurs at flight $b$, the health parameter delta associated with the fault remains fixed in region B. Eq. (9) shows how abrupt fault induced health parameter residuals can be computed. Bleed valve leakage faults or event faults due to foreign object damages can be examples of abrupt faults.

$$
\Delta Z_{A}^{b}=\Delta Z_{T}^{b}-\Delta Z_{G}^{b}
$$

Where $\Delta Z_{A}^{b}$ refers to the health parameter delta which corresponds to the rapid fault event at flight $b, \Delta Z_{G}^{b}$ is the health parameter delta value associated with engine gradual degradation, and $\Delta Z_{T}^{b}$ represents the total health parameter delta when the two degradation mechanisms exist together, at flight $b$.

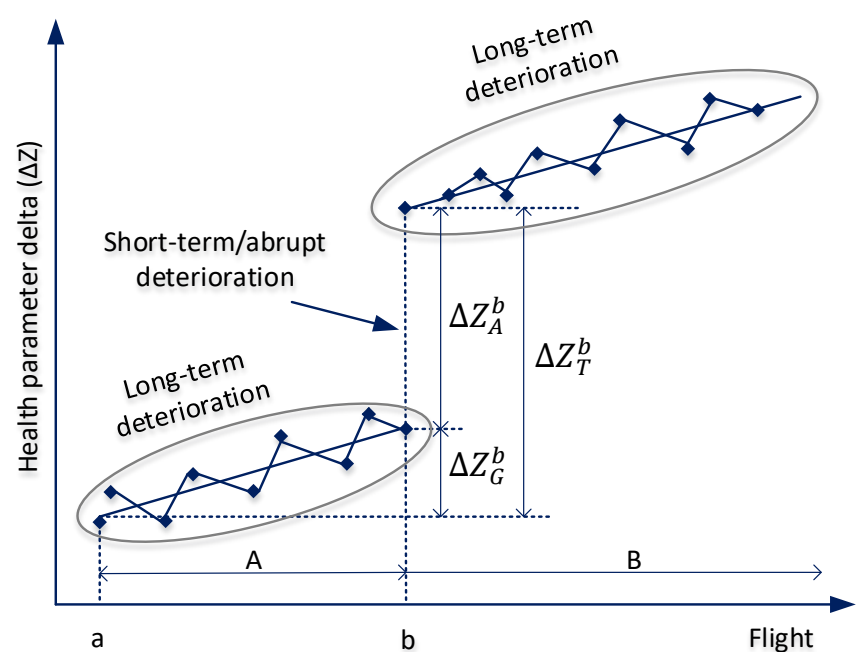

Figure 6. Health parameter delta estimation schematics for engine gradual degradation with an abrupt fault occurrence.

\subsection{Bleed Valve Leakage Identification Using MLP}

A bleed valve leakage is one of the most common gas turbine gas path problems. In normal condition, bleed flows are often considered to be constant fraction of a mainstream flow. Deviation from this value results in a performance loss. Accurate gas path components flow capacity and isentropic efficiency estimation is difficult to perform without an effective leakage fault estimation. A reliable gas path diagnostic system should, therefore, include an effective leakage fault identification. Like with other gas path faults considered in this paper, AGPA can estimate the level of the measured performance change due to bleed valve leakage faults by applying deltas of the gas path components isentropic efficiency and flow capacity parameters. However, it cannot quantify the actual amount of the leakage itself. Instead, as shown in Figure 7, a MLP was applied to estimate IPC and HPC bleed valve leakage faults for the target turbofan engine. MLP is one of the most commonly applied ANN methods in gas turbine diagnostics (Loboda et al., 2018). The engine gas path measurements and two parameters related to magnitude of the two bleed valve leakages were input and output of the structure, respectively.

The performance parameter residuals associated with the two leakage faults, which are estimated by the gas path analysis, were used to generate the input information based on the engine adaptive model. For each leakage faults considered, fault levels up to $10 \%$ were used to generate the training data samples required. A different dataset, but within the domain, was used to evaluate the generalization performance of the model. It should be noted that the input measurements are used after they are filtered and corrected by the AANN and AGPA models, respectively. During practical implementation as well, corrected and filtered measurements need to be used to quantify the magnitude of detected leakage faults by implementing the trained MLP.

Hyperparameters of the optimal model were determined through series of training experiments. Structures with one and two hidden layers were able to provide better results. Increasing the depth of the model further did not change the accuracy significantly. It rather affected the generalization ability of the model. Levenberg-Marquardt training algorithm (Sapna, Tamilarasi, \& Kumar, 2012) was applied, while 1000 epochs were required for the model to converge.

The estimation accuracy of the model for a new dataset was evaluated based on Eq. (10).

$$
R M S E=\sqrt{\frac{1}{n} \sum_{i=1}^{n}\left(P_{B V L}-T_{B V L}\right)^{2}}
$$

where $P_{\mathrm{BVL}}$ is predicted value, $\mathrm{T}_{\mathrm{BVL}}$ is the target value, and $\mathrm{n}$ is the sample size used.

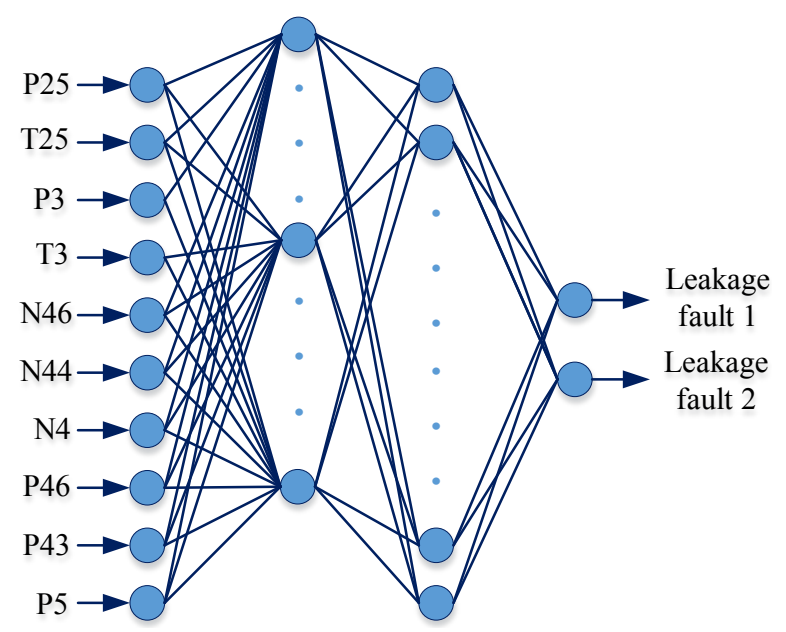

Figure 7. MLP structure used to estimate bleed leakages. All input measurements are corrected and filtered. 


\section{FAULT Simulation}

Although the diagnostic algorithm proposed in this paper is of general validity for three-shaft aircraft engines category, it will be easier to present it through its application to a particular engine type. As shown in Figure 8, the engine under consideration is a three-shaft turbofan engine equipped with a FAN, 2 compressors, a combusted, and 3 turbines designed for 70,000 Ibf thrust. Some specifications of this engine at design point condition can be found in (Zaccaria, Stenfelt, Aslanidou, \& Kyprianidis, 2018).

Before faults can be simulated, the range of performance loss due to gradual degradation is first defined with respect to each health parameter (Table 1) based on the deterioration profile given in (Simon, 2010b). All gas path components are subject to gradual degradation simultaneously, and the level of the degradation depends on the nature of the root cause they are exposed to. In this work, it was assumed to increase linearly with flight cycle and reach the maximum loss at the $5000^{\text {th }}$ flight. The 5000 flights refer to the maximum number of flights assumed that an aircraft engine can perform on average, before overhaul.

A list of the considered fault scenarios with their respective magnitudes is given in Table 2. It consists of five gas path component faults and two bleed valve leakage faults. These fault scenarios were randomly implanted at different flight ranges as shown in Table 2. The fault magnitude (FM) of each component fault was represented in terms of the rootsum-square value of isentropic efficiency and flow capacity deltas, as given through Eq. (11) (Simon, 2010b).

$$
F M=\sqrt{\left[\frac{\eta_{i}-\eta_{r e f}}{\eta_{\text {ref }}}\right]^{2}+\left[\frac{\Gamma_{i}-\Gamma_{r e f}}{\Gamma_{r e f}}\right]^{2}}
$$

For the two compressors, efficiency and flow capacity deltas $(\Delta \eta$ and $\Delta \Gamma$ ) are negative, whereas for the turbines $\Delta \eta$ is negative and $\Delta \Gamma$ is positive. A $2: 1$ ratio between the two health parameter deltas $(\Delta \Gamma: \Delta \eta)$ was assumed.

Table 1. Maximum gradual deterioration considered over the engine operating history.

\begin{tabular}{cccccccccccc}
\hline Component & \multicolumn{2}{c}{ IPC } & \multicolumn{2}{c}{ HPC } & \multicolumn{2}{c}{ HPT } & \multicolumn{2}{c}{ IPT } & \multicolumn{2}{c}{ FPT } \\
\hline Health parameter & $\Delta \eta$ & $\Delta \Gamma$ & $\Delta \eta$ & $\Delta \Gamma$ & $\Delta \eta$ & $\Delta \Gamma$ & $\Delta \eta$ & $\Delta \Gamma$ & $\Delta \eta$ & $\Delta \Gamma$ & number \\
\hline Level of degradation $(\%)$ & -2.5 & -5 & -2.5 & -5 & -1 & 1 & -0.5 & 0.5 & -0.25 & 0.25 & 5000 \\
\hline
\end{tabular}

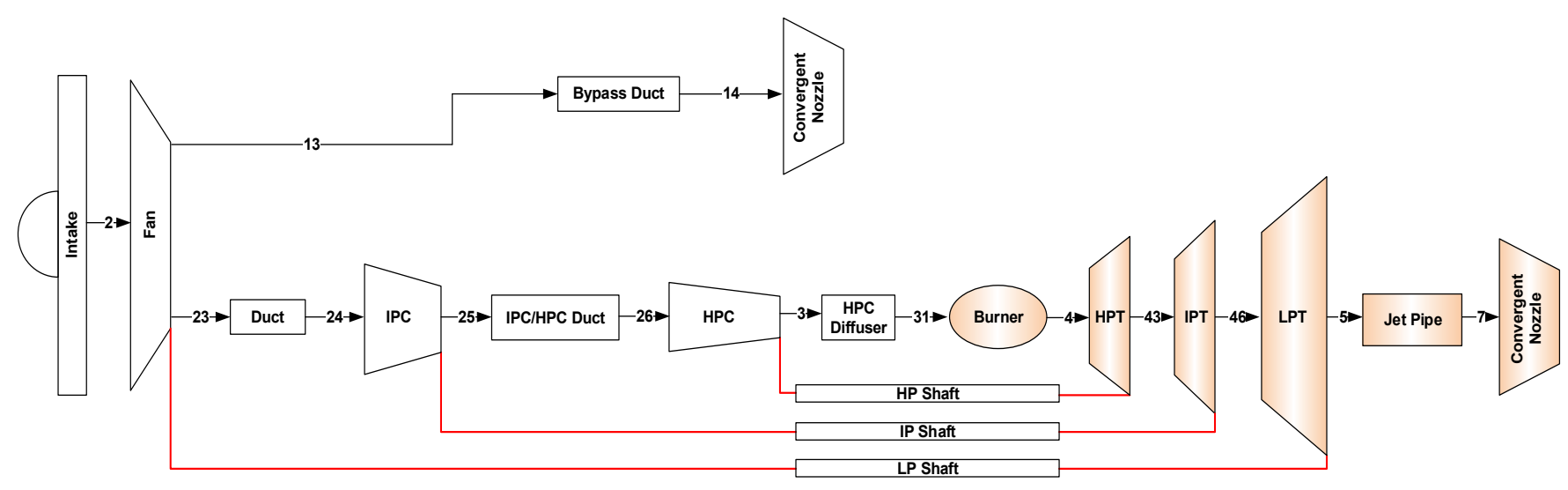

Figure 8. Schematics of three-shaft high-by-pass ratio turbofan engine with measurements locations.

Table 2. Rapid/abrupt fault types considered in selected periods

\begin{tabular}{|c|c|c|c|c|}
\hline Fault description & Fault ID & Fault magnitude & Fault type & Fault evolved flight \\
\hline IPC fault & F1 & Up to $7 \%$ & Rapid fault & $101-150$ \\
\hline HPC fault & $\mathrm{F} 2$ & Up to $7 \%$ & Rapid fault & $501-550$ \\
\hline HPT fault & F3 & Up to $7 \%$ & Rapid fault & $701-750$ \\
\hline IPT fault & F4 & Up to $6 \%$ & Rapid fault & $851-900$ \\
\hline LPT fault & F5 & Up to $6 \%$ & Rapid fault & $1001-1050$ \\
\hline BVL_IPC & F6 & 1 to $7 \%$ & Abrupt fault & $\begin{array}{l}1501-2200(1501-1600=1 \% ; 1601-1700=2 \% \\
1701-1800=3 \% ; 1801-1900=4 \% ; 1901-2000 \\
=5 \% ; 2001-2100=6 \% ; \text { and } 2101-2200=7 \%)\end{array}$ \\
\hline BVL_HPC & F7 & 1 to $7 \%$ & Abrupt fault & $\begin{array}{l}2501-3200(2501-2600=1 \% ; 2601-2700=2 \% ; \\
2701-2800=3 \% ; 2801-2900=4 \% ; 2901-3000 \\
=5 \% ; 3001-3100=6 \% ; \text { and } 3101-3200=7 \%)\end{array}$ \\
\hline
\end{tabular}


All component faults were considered as rapid faults, while the two leakage faults were considered as abrupt faults. Accordingly, fault cases correspond to F1 were implanted to the model from flight number 101 to 150 , randomly. Similarly, fault cases correspond to F2, F3, F4, F5, F6, and F7 were implanted from flight number 501 to 550,701 to 750,851 to 900,1001 to 1050,1501 to 2200 , and 2501 to 3200 , respectively. The component fault scenarios were considered to grow linearly every flight, starting from $0.035 \%$ fault magnitude at their associated flight of fault initiation to the maximum severity. The two abrupt faults were simulated differently in such a way that $1 \%$ leakage fault for 100 flights, $2 \%$ leakage fault for the next 100 flights and so on up to $7 \%$ leakage fault. Here, there is no progress between the adjacent flights within the considered 100 flight range. In all fault scenarios, a discrete data was collected one per each flight at the cruise flight point. Finally, for model robustness against measurement noise effects, significant noise level was considered for each measurement in units of noise standard deviation.

\section{RESULTS AND DISCUSSION}

\subsection{Deterioration Tracking Results of the AGPA (AGPA1 vs. AGPA2)}

The effectiveness of the AGPA scheme to address the defined diagnostic problem was evaluated. We first analysed the performance of the AGPA scheme using noise contaminated measurements. The predicted health indices were then used to predict the measurements at the reference condition (at a standard sea level day condition) using the engine adaptive model. Noise reduction was followed applying a trained AANN model. Due to space limitation, the denoising results are not included in this paper. The interested reader is referred to (Fentaye \& Kyprianidis, 2020). However, the effectiveness of the network and its benefits to improve the diagnostic accuracy can be seen indirectly from the presented AGPA comparison results. We run the AGPA again using the denoised measurements and compare its performance with the one obtained from the noisy measurements. Finally, the estimation accuracy of the AGPA approach were evaluated in terms of the root mean square error (RMSE) statistical parameter as presented in Table 3. An important observation from the statistical analysis is that measurement noise has significant impact on the estimation accuracy of the AGPA. In general, the average RMSE dropped from 0.72 to 0.106 due to the noise reduction. The remaining estimation errors observed were because of the smearing effects of the denoising residuals and parameter correction residuals.
Table 3. AGPA1 vs. AGPA2 engine degradation estimation accuracy evaluation results in terms of RMSE

\begin{tabular}{lcccc}
\hline \multirow{2}{*}{$\begin{array}{l}\text { Health } \\
\text { parameter }\end{array}$} & \multicolumn{2}{c}{ AGPA1 } & \multicolumn{2}{c}{ AGPA2 } \\
\cline { 2 - 5 } & Mean & RMSE & Mean & RMSE \\
\hline$\eta_{\text {IPC }}$ & 0.019 & 0.841 & -0.0004 & 0.086 \\
$\Gamma_{\text {IPC }}$ & 0.006 & 0.532 & -0.0003 & 0.192 \\
$\eta_{\text {HPC }}$ & 0.033 & 1.341 & -0.0012 & 0.090 \\
$\Gamma_{\text {HPC }}$ & 0.008 & 0.877 & -0.0012 & 0.191 \\
$\eta_{\text {HPT }}$ & -0.002 & 1.227 & 0.0000 & 0.102 \\
$\Gamma_{\text {HPT }}$ & 0.002 & 0.479 & 0.0007 & 0.092 \\
$\eta_{\text {IPT }}$ & -0.007 & 0.900 & -0.0036 & 0.124 \\
$\Gamma_{\text {IPT }}$ & 0.003 & 0.455 & -0.0003 & 0.077 \\
$\eta_{\text {LPT }}$ & 0.004 & 0.176 & 0.0003 & 0.029 \\
$\Gamma_{\text {LPT }}$ & 0.008 & 0.376 & 0.0046 & 0.077 \\
\hline
\end{tabular}

The performance trend estimation results achieved are illustrated through Figure 9, with the results obtained from AGPA1 and AGPA2 (that means diagnostic results before and after the denoising process) being compared. It is clearly seen that the AGPA results obtained from the denoised measurements can better show the trends of performance changes. Since only two performance parameters at a time are changing for each component fault, component faults can be isolated easily based on the AGPA outputs. Likewise, as more than two health parameters are simultaneously changing for leakage faults, they can be differentiated easily from component faults. Particularly, among the ten health parameters considered, the IPC and HPC efficiency deltas associated with the two leakage faults were very close to the changes due to the gradual deterioration. This indicates that these two health parameters cannot be used to detect leakage faults. On the other hand, the remaining eight health parameters are equally important to detect the existence of the two leakage faults including clearly distinguishing the severity levels. However, as these eight health parameter deviation patterns are similar for both fault types, another parameter needs to be considered to differentiate one leakage fault from the other. For this purpose, the measurement parameter T3 was selected since it showed different patterns, as illustrated through Figure 10 (a). This figure refers to the trend of T3 measurement changes predicted by the adaptive model based on AGPA2 outputs. One can see that the leakage that comes from the IPC bleed valve results in an increase in the HPC delivery temperature. On the other hand, the leakage that comes from the HPC bleed valve results in a decrease in the HPT delivery temperature. Equivalently, as shown in Figure 10 (b), a plot of the denoised T3, that is prior to the process in AGPA2, can also be used for the same purpose. 

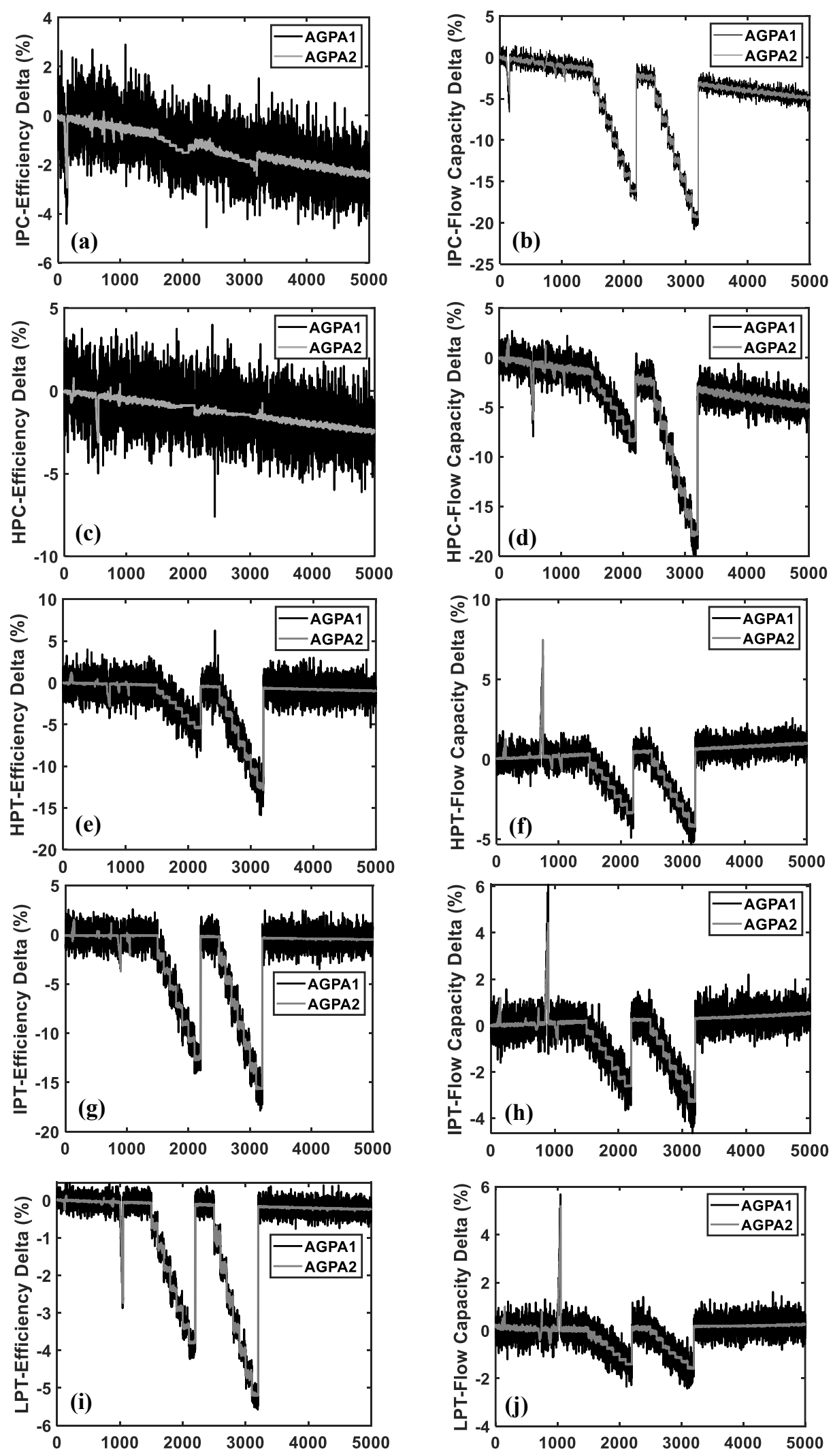

Figure 9. Comparison between AGPA1 and AGPA2 results for 5000 flight cycles: (a) $\eta_{\mathrm{IPC}}$, (b) $\Gamma_{\mathrm{IPC}},(\mathrm{c}) \eta_{\mathrm{HPC}}$, (d) $\Gamma_{\mathrm{HPC}}$, (e) $\eta_{\mathrm{HPT}}$, (f) $\Gamma_{\mathrm{HPT}},(\mathrm{g}) \eta_{\mathrm{IPT}},(\mathrm{h}) \Gamma_{\mathrm{IPT}}$, (i) $\eta_{\mathrm{LPT}}$, and (j) $\Gamma_{\mathrm{LPT}}$ 

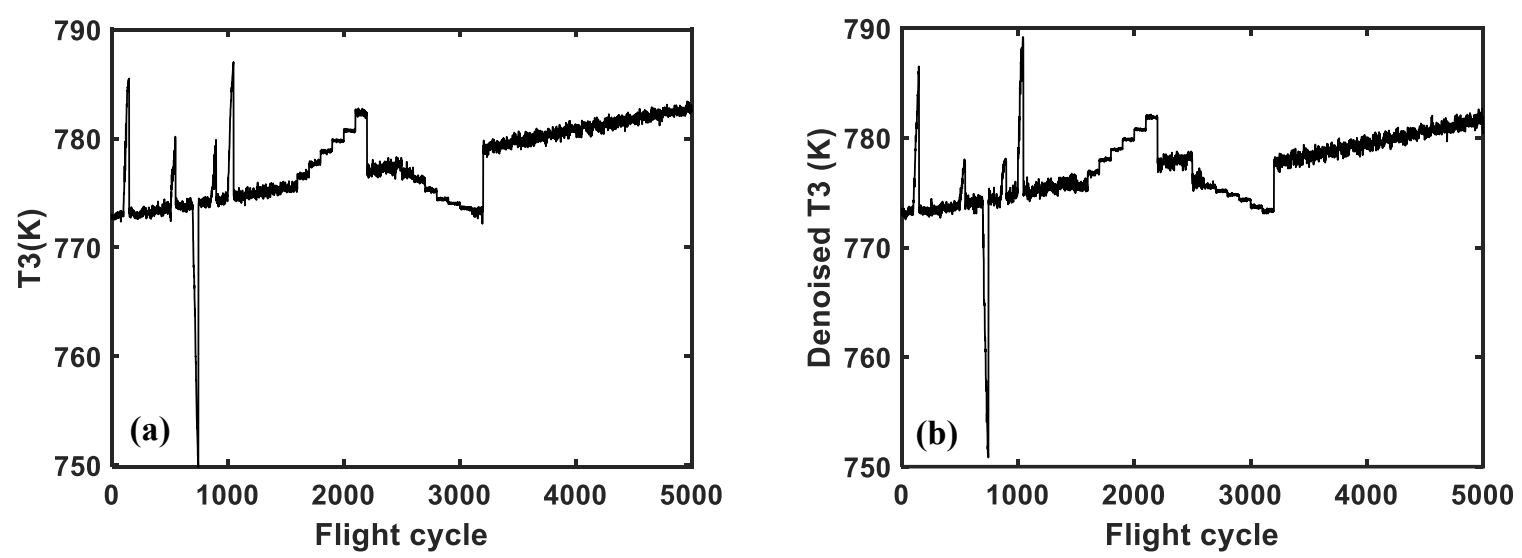

Figure 10. T3 trend for 5000 flight cycles: (a) T3 estimated by the adaptive model based on AGPA2 outputs and (b) T3 after the denoising process through AANN1

\subsection{Fault Isolation and Identification Results}

As explained in Section 4.3, AANN2 is integrated with AGPA2 for the purpose of isolating and identifying rapid/abrupt faults considered in this paper. AGPA2 estimates the total health parameter deltas caused by gradual degradation when it exists individually or together with a rapid/abrupt fault. However, net health parameter deltas are necessary for the fault isolation and identification process. For this reason, the performance deltas due to gradual deterioration form the baseline, which is estimated by AANN2. Health parameter deltas that only correspond to rapid/abrupt faults are then computed by subtracting the deltas corresponding to gradual degradation from the total deltas estimated by AGPA2. In the only presence of gradual degradation, the estimated net health parameter deltas are expected to be close to zero or fall within some defined threshold. For deltas that exceed the threshold, faults are isolated based on which health parameters are showing significant changes.

Taking into account model estimation errors and to avoid unnecessary maintenance downtimes, delta values within the range of $\pm 0.25 \%$ were assumed to be no-fault residuals. Efficiency and flow capacity health indicators corresponding to $\mathrm{FM}= \pm 0.25 \%(\Delta \eta= \pm 0.112$ and $\Delta \Gamma=$ \pm 0.224 ) are selected as the upper and lower threshold limits. These health indicators were calculated by applying Eq. (11) based on a 1:2 ratio. Figure 11 demonstrates the detection results achieved for each one of the ten health parameters considered.

According to Table 2, the considered seven faults are assumed to occur within the following flight numbers individually: $\mathrm{F} 1\left(\Delta \eta_{\mathrm{IPC}}, \Delta \Gamma_{\mathrm{IPC}}\right)$ between 151 and 200 , F2 $\left(\Delta \eta_{\mathrm{HPC}}, \Delta \Gamma_{\mathrm{HPC}}\right)$ between 501 and 550, F3 $\left(\Delta \eta_{\mathrm{HPT}}, \Delta \Gamma_{\mathrm{HPT}}\right)$ between 701 and $750, \mathrm{~F} 4\left(\Delta \eta_{\text {IPT }}, \Delta \Gamma_{\text {IPT }}\right)$ between 851 and 900, F5 $\left(\Delta \eta_{\mathrm{LPT}}, \Delta \Gamma_{\mathrm{LPT}}\right)$ between 1001 and 1050, F6 between 1501 and 2200, and F7 between 2501 and 3200 flight cycles. In the case of F6 and F7, all the ten health parameters deltas are expected to exceed their thresholds at the same time. Because the occurrence of these two faults affects the health parameters of all gas path components together. If these seven faults are detected outside the range of flight numbers they are assumed to exist, that is due to the model smearing effects. With this context, we can generally examine the detection accuracy of the method based on Figure 11. As illustrated through Figure 11 (a) and (b), F1, F6 and F7 are detected correctly within the range of the flight numbers they are considered to occur. The detected faults indicated by the broken dark blue section refers to the smearing effects. Summary of the correctly diagnosed faults and the smearing effects based on the results illustrated through Figure 11 is provided in Table 4. In most of the isentropic efficiency health parameters, the smearing effect reaches up to $\pm 1 \%$. On the other hand, the effect for most of flow capacity parameters is approximately twice of the effect on the efficiency parameters. This difference is observed due to the difference in the magnitude of the faults considered corresponding to the two health parameters. It can be concluded here is that the AGPA-ANN method is capable of detecting and identifying the considered seven gas path faults, but the smearing effects are problematic.

Table 4. Summary of detected faults and smearing effects based on Figure 11

\begin{tabular}{ccccc}
\hline Figure 11 & $\begin{array}{c}\text { Health } \\
\text { parameter }\end{array}$ & $\begin{array}{c}\text { Expected } \\
\text { fault }\end{array}$ & $\begin{array}{c}\text { Detected } \\
\text { fault }\end{array}$ & $\begin{array}{c}\text { Smearing } \\
\text { effects }\end{array}$ \\
\hline (a) and (b) & $\Delta \eta_{\text {IPC } \&}$ & F1, F6, & F1, F6, & F2, F3, \\
& $\Delta \Gamma_{\text {IPC }}$ & and F7 & and F7 & F4, and F5 \\
(c) and (d) & $\Delta \eta_{\text {HPC } \&}$ & F2, F6, & F2, F6, & F1, F3, \\
& $\Delta \Gamma_{\text {HPC }}$ & and F7 & and F7 & F4, and F5 \\
(e) and (f) & $\Delta \eta_{\text {HPT } \&}$ & F3, F6, & F3, F6, & F1, F2, \\
& $\Delta \Gamma_{\text {HPT }}$ & and F7 & and F7 & F4, and F5 \\
(g) and (h) & $\Delta \eta_{\text {IPT } \&}$ & F4, F6, & F4, F6, & F1, F3, \\
& $\Delta \Gamma_{\text {IPT }}$ & and F7 & and F7 & and F5 \\
(i) and (j) & $\Delta \eta_{\text {LPT \& }}$ & F5, F6, & F5, F6, & F1, F3, \\
& $\Delta \Gamma_{\text {LPT }}$ & and F7 & and F7 & and F4 \\
\hline
\end{tabular}



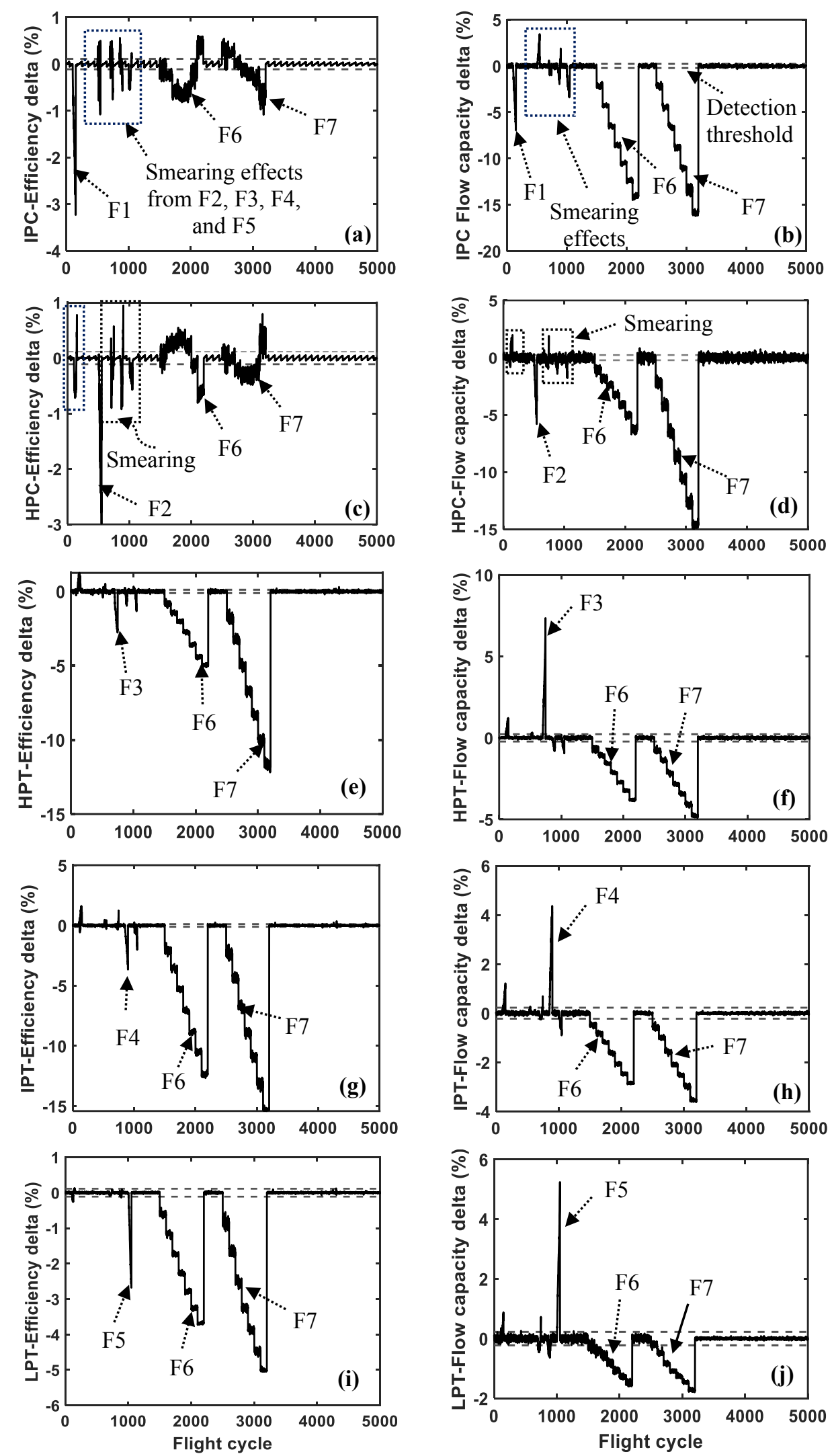

Figure. 11. AANN based rapid/abrupt fault detection, isolation and identification results. (a) for $\eta_{\text {IPC }}$, (b) for $\Gamma_{\mathrm{IPC}}$, (c) for $\eta_{\mathrm{HPC}}$, (d) for $\Gamma_{H P C},(e)$ for $\eta_{H P T}$, (f) for $\Gamma_{H P T}(g)$ for $\eta_{I P T},(h)$ for $\Gamma_{I P T}$, (i) for $\eta_{L P T}$, and (j) for $\Gamma_{L P T}$ 
Based on the standard detection decision matrix approach (Simon, 2010b), the detection accuracy of the method was evaluated in terms of true positive rate (TPR), false positive rate (FPR), true negative rate (TNR), and false negative rate (FNR). According to the assessment results presented in Table 5, the maximum detection accuracy recorded is for $\eta_{\text {LPT }}(99.65 \%)$, while the minimum accuracy is achieved for the $\Gamma_{\text {HPC }}(84.96 \%)$. The FPR for the $\Gamma_{\text {HPC }}$ parameter is quite high $(21.1 \%)$, as it will lead to added-costs due to high rate of unnecessary maintenance downtimes. Nevertheless, changing the detection threshold from $\pm 0.25 \%$ to $\pm 0.5 \%$ can reduce this value to $2.6 \%$ with only a $6 \%$ decrease in the TPR. Generally, it has been observed that the overall detection accuracy can be improved by

- increasing the detection threshold. Increasing the lower possible detectable fault from $\pm 0.25 \%$ to, for instance, $1 \%$ (i.e., $\Delta \eta= \pm 0.447$ and $\Delta \Gamma= \pm 0.894$ ) can increase the overall detection accuracy significantly. Because, as can be seen in Figure 11, great majority of the smearing effects and $100 \%$ of the other no-fault flight data fall within this range. In real-time situations, estimation errors and issues related to maintenance downtimes should be taken into consideration while setting detection thresholds.

- excluding $\eta_{\text {IPC }}$ and $\eta_{\text {HPC }}$ from the set of health parameters that are used to detect BVL-IPC and BVLHPC can increase their average detection accuracy to $94.82 \%$ and $94.84 \%$, respectively. Because, as illustrated through Figure 11 (a) and (b), these two parameters exhibit the highest false detection and magnitude estimation errors for these leakage faults.

- improving the estimation accuracy of the AGPA, possibly by enhancing the denoising effectiveness. This obviously decreases the smearing effect, and thereby decreases the FAR. This can also improve the fault identification accuracy of the method.

In general, the detection and quantification accuracy of the integrated AGPA-AANN method was influenced by the smearing effects from the AGPA. This is because of noise

Table 5. Fault detection accuracy assessment results

\begin{tabular}{cccccc}
\hline $\begin{array}{c}\text { Health } \\
\text { parameter }\end{array}$ & TPR & FPR & TNR & FNR & ODA \\
\hline$\eta_{\text {IPC }}$ & 70.9 & 7.3 & 92.7 & 29.1 & 86.40 \\
$\Gamma_{\text {IPC }}$ & 99.9 & 7.2 & 92.8 & 0.1 & 94.84 \\
$\eta_{\text {HPC }}$ & 80.4 & 4.8 & 95.2 & 19.6 & 90.90 \\
$\Gamma_{\text {HPC }}$ & 99.7 & 21.1 & 78.9 & 0.3 & 84.96 \\
$\eta_{\text {HPT }}$ & 99.8 & 7.2 & 92.8 & 0.2 & 94.80 \\
$\Gamma_{\text {HPT }}$ & 99.7 & 3.1 & 96.9 & 0.3 & 97.68 \\
$\eta_{\text {IPT }}$ & 99.9 & 5.3 & 94.7 & 0.1 & 96.22 \\
$\Gamma_{\text {IPT }}$ & 99.6 & 0.4 & 97.6 & 2.4 & 98.16 \\
$\eta_{\text {LPT }}$ & 99.7 & 0.3 & 99.7 & 0.3 & 99.68 \\
$\Gamma_{\text {LPT }}$ & 91.7 & 2.8 & 97.2 & 8.3 & 95.62 \\
\hline
\end{tabular}

and the large number of degraded components considered (Ying et al., 2016). The smearing effect was observed higher for compressor faults than turbine faults. Normally, the accuracy of a gas path analysis for component level degradation estimation depends on the number, type and location of measurements used, and how optimal the combination is (Ogaji, Sampath, Singh, \& Probert, 2002). But in this particular work, the observed small smearing effect difference seems to be due to the difference in the fault magnitude considered for the target engine compressors and turbines, as can be seen in Table 2, and/or the leakage faults imposed on the two compressors. However, incorporating the denoising AANN minimized the smearing effects considerably and improved the diagnostic accuracy of the model quite significantly. This indicates that the major smearing effect was caused by measurement noise, and as a result, further investigations on more effective noise minimization is necessary. Nevertheless, all the detected faults were able to be isolated correctly.

\subsection{Leakage Fault Identification Results}

The magnitude of the two leakage faults is estimated by implementing an MLP model using the corrected gas path measurements as input information. As can be seen in Figure 11, leakage faults can easily be differentiated from the component faults since more than two health parameters deviate simultaneously upon their occurrence. Besides, the health parameter indices obtained from the AGPA can indicate the severity of the detected leakage fault indirectly. However, it cannot estimate the percentage magnitude of the leakage itself. A single hidden layer was, therefore, implemented to perform this task. Two hundred sample data points were used to train the model. Leakage values ranging from 0 to $10 \%$ were considered to generate the training dataset. Here, fault levels higher than $7 \%$ (that means higher values from the ones defined in Table 2) were considered aiming to increase the working space of the network.

After completing the training process, unseen test data samples, which represent different leakage severities, were considered to evaluate the estimation performance of the model. Figure 12 illustrates the test results obtained from the MLP in comparison with the implanted fault values (or target values). The flights from 1500 to 2200 (1\% leakage fault for 100 flights, from 1501 to 1600 flights, 2\% leakage fault for another 100 flights, from 1601 to 1700 flights, and so on until 7\% leakage faults, from 2101 to 2200 flights) refers to the BVL-IPC fault. Likewise, the flights from 2500 to 3200 are dedicated to BVL-HPC fault. As can be seen in this figure, the model estimated percentage leakage values seem to be very close to the implanted percentage leakage values in most of the cases. The overall performance of the MLP for the BVL-IPC and BVL_HPC has been evaluated in terms of RMSE, and 0.221 and 0.311 are the results achieved, respectively. This performance may further be improved by enhancing the AGPA predication accuracy. 


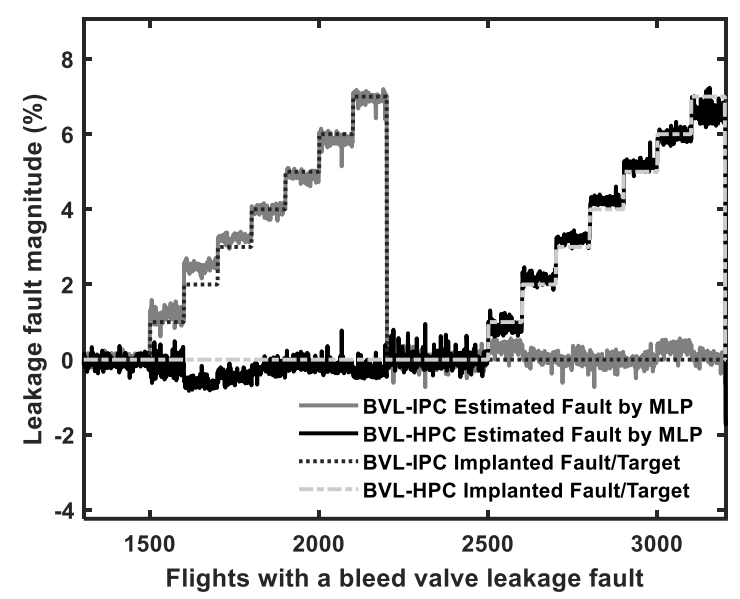

Figure 12. Bleed valve leakage faults estimated by the MLP vs. implanted or target values

\section{CONCLUSIONS AND FUTURE WORKS}

An approach based on the combination of adaptive gas path analysis and artificial neural network framework was investigated for long-term and short-term degradation monitoring and diagnostics. This framework was devised to perform three main activities: measurement noise removal, short-term and long-term deterioration discrimination, and fault isolation and identification. The gas path analysis is dedicated to track component level performance trends in order to provide a preliminary information about the two degradation modes. Upon fault detection, the observed faulty signature vector is supplied as input information to the trained neural network modules to isolate and identify the detected faults. Seven different fault scenarios, in a three-shaft high-bypass turbofan engine, were considered to demonstrate and evaluate the performance of this method. The test results revealed that the proposed method can successfully discriminate long-term and short-term deterioration modes and isolate and identify the seven different fault types considered. It was observed that the accuracy of the neural networks depends on the effectiveness of the gas path analysis. Besides, the effectiveness of the latter was influenced by smearing effects due to measurement noise residuals. Finally, the following improvements are recommended to increase the benefit of the proposed method for engine health management:

- Applying a more reliable degradation profile, based on practical information, while simulating the engine gradual deterioration

- Extending the presented procedure to handle other fault scenarios such as sensor faults and baseline shifts upon maintenance events.

- Adding more realism to the diagnostic problem including engine-to-engine variations and flightto-flight variations in operating conditions.

\section{ACKNOWLEDGEMENT}

The authors graciously acknowledge the Knowledge Foundation (KKS) for supporting this research financially under the DIAGNOSIS and PROGNOSIS projects.

\section{REFERENCES}

Aretakis, N., Mathioudakis, K., \& Stamatis, A. (2003). Nonlinear Engine Component Fault Diagnosis From a Limited Number of Measurements Using a Combinatorial Approach. Journal of Engineering for Gas Turbines and Power, 125(3), 642-650. doi:10.1115/1.1582494

Bai, M., Liu, J., Chai, J., Zhao, X., \& Yu, D. (2020). Anomaly detection of gas turbines based on normal pattern extraction. Applied Thermal Engineering, 166, 114664.doi:https://doi.org/10.1016/j.applthermaleng.201 9.114664

Boyce, M. P., \& Gonzalez, F. (2005). A Study of On-Line and Off-Line Turbine Washing to Optimize the Operation of a Gas Turbine. Journal of Engineering for Gas Turbines and Power, 129(1), 114-122. doi: $10.1115 / 1.2181180$

Dewallef, P., Romessis, C., Léonard, O., \& Mathioudakis, K. (2004). Combining Classification Techniques With Kalman Filters for Aircraft Engine Diagnostics. Journal of Engineering for Gas Turbines and Power, 128(2), 281-287. doi:10.1115/1.2056507

Fentaye, A. D., Baheta, A. T., Gilani, S. I., \& Kyprianidis, K. G. (2019). A Review on Gas Turbine Gas-Path Diagnostics: State-of-the-Art Methods, Challenges and Opportunities. Aerospace, 6(7), 83. doi:https://doi.org/10.3390/aerospace6070083

Fentaye, A. D., \& Kyprianidis, K. G. (2020). An intelligent data filtering and fault detection method for gas turbine engines. ICSC \& ISATECH, 9 - 11 Oct., 2019, Amsterdam, the Netherlands. doi: https://doi.org/10.1051/matecconf/202031402007

Fentaye, A. D., Ul-Haq Gilani, S. I., Baheta, A. T., \& Li, Y.-G. (2018). Performance-based fault diagnosis of a gas turbine engine using an integrated support vector machine and artificial neural network method. Proceedings of the Institution of Mechanical Engineers, Part A: Journal of Power and Energy, 233(6), 786-802. doi:10.1177/0957650918812510

Fentaye Amare, D., Baheta Aklilu, T., \& Gilani Syed Ihtsham, U.-H. (2018). Gas turbine gas-path fault identification using nested artificial neural networks. Aircraft Engineering and Aerospace Technology, 90(6), 992-999. doi:10.1108/AEAT-01-2018-0013

Ganguli, R. (2002). Noise and outlier removal from jet engine health signals using weighted FIR median hybrid filters. Mechanical Systems and Signal Processing, 16(6), 967-978. https://doi.org/10.1006/mssp.2002.1477

Ganguli, R. (2003). Application of fuzzy logic for fault isolation of jet engines. Journal of Engineering for Gas 
Turbines and Power, 125(3), 617-623. doi:https://doi.org/10.1115/1.1470481

Hanachi, H., Liu, J., Banerjee, A., \& Chen, Y. (2015). A framework with nonlinear system model and nonparametric noise for gas turbine degradation state estimation. Measurement Science and Technology, 26(6), 065604. doi:10.1088/0957-0233/26/6/065604

Hanachi, H., Liu, J., Kim, I. Y., \& Mechefske, C. K. (2019). Hybrid sequential fault estimation for multi-mode diagnosis of gas turbine engines. Mechanical systems and signal processing, 115, 255-268. doi:https://doi.org/10.1016/j.ymssp.2018.05.054

Jaw, L. C., \& Lee, Y.-J. (2014). Engine diagnostics in the eyes of machine learning. Proceedings of the 2014 ASME Turbo Expo, June 16-20, 2014, Düsseldorf, Germany. doi: https://doi.org/10.1115/GT2014-27088

Jiang, X., \& Foster, C. (2013). Remote Thermal Performance Monitoring and Diagnostics: Turning Data Into Knowledge. ASME 2013 Power Conference, July 29-August 1, 2013, Boston, Massachusetts, USA. doi:10.1115/POWER2013-98246

Koskoletos, A. O., Aretakis, N., Alexiou, A., Romesis, C., \& Mathioudakis, K. (2018). Evaluation of Aircraft Engine Gas Path Diagnostic Methods Through ProDiMES. Journal of Engineering for Gas Turbines and Power, 140(12). doi: https://doi.org/10.1115/1.4040909

Kramer, M. A. (1991). Nonlinear principal component analysis using autoassociative neural networks. AIChE journal, 37(2), 233-243. doi: https://doi.org/10.1002/aic.690370209

Kyprianidis, K. (2017). An Approach to Multi-Disciplinary Aero Engine Conceptual Design. International Symposium on Air Breathing Engines, ISABE 2017, Manchester, United Kingdom, 3-8 September 2017 Paper No. ISABE-2017-22661.

Kyprianidis, K. (2019). On Gas Turbine Conceptual Design. Ph.D. thesis, Cranfield University, UK.

Lambiris, B., Mathioudakis, K., Stamatis, A., \& Papailiou, K. (1994). Adaptive modeling of jet engine performance with application to condition monitoring. Journal of propulsion and power, 10(6), 890-896. doi:https://doi.org/10.2514/3.23828

Lee, Y. K., Mavris, D. N., Volovoi, V. V., Yuan, M., \& Fisher, T. (2010). A fault diagnosis method for industrial gas turbines using Bayesian data analysis. Journal of Engineering for Gas Turbines and Power, 132(4), 041602. doi:https://doi.org/10.1115/1.3204508

Li, Y.-G. (2017). Diagnostics of power setting sensor fault of gas turbine engines using genetic algorithm. The Aeronautical Journal, 121(1242), 1109-1130. doi:

Li, Y. (2010). Gas turbine performance and health status estimation using adaptive gas path analysis. Journal of Engineering for Gas Turbines and Power, 132(4), 041701. doi: https://doi.org/10.1115/1.3159378

Litt, J. S., Parker, K. I., \& Chatterjee, S. (2003). Adaptive gas turbine engine control for deterioration compensation due to aging. Technical Report TM 2003212607, NASA Glenn, Lewis, Ohio.

Loboda, I., \& Olivares Robles, M. A. (2015). Gas turbine fault diagnosis using probabilistic neural networks. International Journal of Turbo \& Jet-Engines, 32(2), 175-191. doi: 10.1515/tjj-2014-0019

Loboda, I., Pérez-Ruiz, J. L., \& Yepifanov, S. (2018). A benchmarking analysis of a data-driven gas turbine diagnostic approach. Proceedings of ASME Turbo Expo 2018, Turbomachinery Technical Conference and Exposition, June 11-15, 2018, Oslo, Norway. doi: https://doi.org/10.1115/GT2018-76887

Losi, E., Venturini, M., Manservigi, L., Ceschini, G. F., \& Bechini, G. (2019). Anomaly Detection in Gas Turbine Time Series by Means of Bayesian Hierarchical Models. Journal of Engineering for Gas Turbines and Power, 141(11).

Lu, F., Gao, T., Huang, J., \& Qiu, X. (2019). A novel distributed extended Kalman filter for aircraft engine gas-path health estimation with sensor fusion uncertainty. Aerospace Science and Technology, 84, 90106. doi:https://doi.org/10.1016/j.ast.2018.10.019

Marinai, L., Probert, D., \& Singh, R. (2004). Prospects for aero gas-turbine diagnostics: a review. Applied Energy, $79(1)$ 109-126. doi:http://dx.doi.org/10.1016/j.apenergy.2003.10.005

Marinai, L., Singh, R., Curnock, B., \& Probert, D. (2003). Detection and prediction of the performance deterioration of a turbofan engine. Proceedings of the International Gas Turbine Congress, November 2-7, 2003, Tokyo, Japan.

Mathioudakis, K., \& Kamboukos, P. (2004). Assessment of the Effectiveness of Gas Path Diagnostic Schemes. Journal of Engineering for Gas Turbines and Power, 128(1), 57-63. doi:10.1115/1.1924535

Mathioudakis, K., \& Romessis, C. (2016). Probabilistic neural networks for validation of on-board jet engine data. Proceedings of the Institution of Mechanical Engineers, Part G: Journal of Aerospace Engineering, 218(1), 59-72. doi:10.1177/095441000421800105

Mohammadi, E., \& Montazeri-Gh, M. (2015). A fuzzybased gas turbine fault detection and identification system for full and part-load performance deterioration. Aerospace Science and Technology, 46, 82-93. doi:http://dx.doi.org/10.1016/j.ast.2015.07.002

Ogaji, S. O. T., Sampath, S., Singh, R., \& Probert, S. D. (2002). Parameter selection for diagnosing a gasturbine's performance-deterioration. Applied Energy, 73(1), 25-46. doi:https://doi.org/10.1016/S03062619(02)00042-9

Pourbabaee, B., Meskin, N., \& Khorasani, K. (2015). Sensor Fault Detection, Isolation, and Identification Using Multiple-Model-Based Hybrid Kalman Filter for Gas Turbine Engines. in IEEE Transactions on Control Systems Technology, vol. 24, no. 4, pp. 1184-1200, July 2016. doi:10.1109/TCST.2015.2480003. 
Roumeliotis, I., Aretakis, N., Mathioudakis, K., \& Yfantis, E. A. (2012). Modelling and Assessment of Compressor Faults on Marine Gas Turbines. ASME Turbo Expo 2012: Turbine Technical Conference and Exposition, June 11-15, 2012, Copenhagen, Denmark. doi:https://doi.org/10.1115/GT2012-69740

Sadough Vanini, Z. N., Meskin, N., \& Khorasani, K. (2014). Multiple-model sensor and components fault diagnosis in gas turbine engines using autoassociative neural networks. Journal of Engineering for Gas Turbines and Power, 136(9). doi:https://doi.org/10.1115/1.4027215

Sapna, S., Tamilarasi, A., \& Kumar, M. P. (2012). Backpropagation learning algorithm based on Levenberg Marquardt Algorithm. Comp Sci Inform Technol (CS and IT), 2, 393-398. doi: 10.5121/csit.2012.2438

Saxena, A., Goebel, K., Simon, D., \& Eklund, N. (2008). Damage propagation modeling for aircraft engine run-tofailure simulation. International conference on prognostics and health management. 6-9 Oct. 2008, Denver, CO, USA. doi:10.1109/PHM.2008.4711414

Simon, D. L. (2010a). An integrated architecture for onboard aircraft engine performance trend monitoring and gas path fault diagnostics. Proceedings of the 2010 JANNAF Joint Subcommittee Meeting, Colorado Springs, CO, May 3-7. doi:10.2514/6.2014-3924

Simon, D. L. (2010b). Propulsion diagnostic method evaluation strategy (ProDiMES) user's guide. NASA/TM-2010-215840. doi: 20100005639

Simon, D. L., Borguet, S., Léonard, O., \& Zhang, X. F. (2014). Aircraft engine gas path diagnostic methods: public benchmarking results. Journal of Engineering for Gas Turbines and Power, 136(4), 041201.doi: https://doi.org/10.1115/1.4025482

Stenfelt, M., Zaccaria, V., \& Kyprianidis, K. G. (2019). Automatic gas turbine matching scheme adaptation for robust GPA diagnostics. Proceedings of the ASME Turbo Expo 2019: Power for Land, Sea and Air, June 11-15, 2019, Phoenix, Arizona, USA. GT2019-91018. doi:https://doi.org/10.1115/GT2019-91018

Tahan, M., Tsoutsanis, E., Muhammad, M., \& Karim, Z. A. (2017). Performance-based health monitoring, diagnostics and prognostics for condition-based maintenance of gas turbines: A review. Applied Energy, 198, 122-144. doi: https://doi.org/10.1016/j.apenergy.2017.04.048

Tang, S., Tang, H., \& Chen, M. (2019). Transfer-learning based gas path analysis method for gas turbines. Applied Thermal Engineering, 155, 1-13. doi: https://doi.org/10.1016/j.applthermaleng.2019.03.156

Uday, P., \& Ganguli, R. (2010). Jet engine health signal denoising using optimally weighted recursive median filters. Journal of Engineering for Gas Turbines and Power, 132(4). doi: https://doi.org/10.1115/1.3200907
Urban, L. A. (1969). Gas turbine engine parameter interrelationships: $2 \mathrm{~d}$ ed. Hamilton Standard Division of United Aircraft Windsor Locks, USA.

Van der A., H., Anthonis, J., De Bruyne, S., \& Leuridan, J. J. E. w. C. (2013). Virtual engineering at work: the challenges for designing mechatronic products. 29(3), 389-408.doi:10.1007/s00366-012-0286-6

Wei, Z., Zhang, S., Jafari, S., \& Nikolaidis, T. (2020). Gas turbine aero-engines real time on-board modelling: A review, research challenges, and exploring the future. Progress in Aerospace Sciences, 121, 100693. doi: https://doi.org/10.1016/j.paerosci.2020.100693

Verma, R., \& Ganguli, R. (2005). Denoising jet engine gas path measurements using nonlinear filters. IEEE/ASME Transactions on Mechatronics, 10(4), 461-464. doi: 10.1109/TMECH.2005.852454

Visser, W. P. J., Kogenhop, O., \& Oostveen, M. (2004). A Generic Approach for Gas Turbine Adaptive Modeling. Journal of Engineering for Gas Turbines and Power, 128(1), 13-19. doi:10.1115/1.1995770

Volponi, A. J. (2014). Gas Turbine Engine Health Management: Past, Present, and Future Trends. Journal of Engineering for Gas Turbines and Power, 136(5), 051201. doi:10.1115/1.4026126

Xuyun, F., Hui, L., Zhong, S., \& Lin, L. (2019). Aircraft engine fault detection based on grouped convolutional denoising autoencoders. Chinese Journal of Aeronautics, 32(2),296-307. doi:https://doi.org/10.1016/j.cja.2018.12.011

Ying, Y., Cao, Y., Li, S., Li, J., \& Guo, J. (2016). Study on gas turbine engine fault diagnostic approach with a hybrid of gray relation theory and gas-path analysis. Advances in Mechanical Engineering, 8(1), 1687814015627769. doi:https://doi.org/10.1177/1687814015627769

Zaccaria, V., Stenfelt, M., Aslanidou, I., \& Kyprianidis, K. G. (2018). Fleet Monitoring and Diagnostics Framework Based on Digital Twin of Aero-Engines. Proceedings of ASME Turbo Expo 2018, Turbomachinery Technical Conference and Exposition, June 11-15, 2018, Oslo, Norway. doi:https://doi.org/10.1115/GT2018-76414

Zedda, M., \& Singh, R. (2002). Gas turbine engine and sensor fault diagnosis using optimization techniques. Journal of propulsion and power, 18(5), 1019-1025. doi:https://doi.org/10.2514/2.6050

Zhao, N., Wen, X., \& Li, S. (2016). A Review on Gas Turbine Anomaly Detection for Implementing Health Management. ASME Turbo Expo 2016: Turbomachinery Technical Conference and Exposition, June 13-17, 2016, Seoul, South Korea, Harbin, China. doi:10.1115/GT2016-58135

Zhou, D., Zhang, H., \& Weng, S. (2015). A New Gas Path Fault Diagnostic Method of Gas Turbine Based on Support Vector Machine. Journal of Engineering for Gas Turbines and Power, 137(10), 102605. doi:10.1115/1.4030277 